\title{
Birth characteristics and all-cause mortality: A sibling analysis using the Uppsala Birth Cohort Multigenerational Study
}

\author{
Sol Juárez ${ }^{1,2}$, Anna Goodman, ${ }^{1,3}$ Bianca De Stavola ${ }^{3}$, Ilona Koupil ${ }^{1,4}$
}

1 Centre for Health Equity Studies (CHESS), Stockholm University/Karolinska Institute, Stockholm, Sweden

2 Division of Occupation and Environmental Medicine, Lund University, Lund, Sweden 3 London School of Hygiene and Tropical Medicine, London, UK

4 Department of Public Health Sciences, Karolinska Institute, Stockholm, Sweden

Corresponding author: S. Juárez, Centre for Health Equity Studies, Stockholm University/Karolinska Institute, Sveavägen 160, Sveaplan, Stockholm, Sweden. (Email sol.juarez@chess.su.se)

Note: this is a personal version, created by Anna Goodman, of the text of the accepted journal article. It reflects all changes made in the peer review process, but does not incorporate any minor modifications made at the proof stage. The complete citation for the final journal article is:

- Juárez, S., Goodman, A., De Stavola, B. \& Koupil, I. 2016a. Birth characteristics and all-cause mortality: a sibling analysis using the Uppsala birth cohort multigenerational study. J Dev Orig Health Dis, 7, 374-83

- DOI: $10.1017 / \mathrm{S} 2040174416000179$

Copyright (C) and Moral Rights for this paper are retained by the individual authors and/or other copyright owners 


\begin{abstract}
$\underline{\text { Abstract }}$
This paper investigates the association between perinatal health and all-cause mortality for specific age intervals, assessing the contribution of maternal socioeconomic characteristics and the presence of maternal-level confounding. Our study is based on a cohort of 12,564 singletons born between 1915 and 1929 at the Uppsala University Hospital. We fitted Cox regression models to estimate age-varying hazard ratios of allcause mortality for absolute and relative birthweight and for gestational age. We found that associations with mortality vary by age and according to the measure under scrutiny, with effects being concentrated in infancy, childhood or early adult life. For example, the effect of low birthweight was greatest in the first year of life (HR 2.82) and then continues up to 44 years of age (HR between 1.19 and 1.51). These associations were confirmed in within-family analyses, which provided no evidence of residual confounding by maternal characteristics. Our findings support the interpretation that policies oriented towards improving population health should invest in birth outcomes and hence in maternal health.
\end{abstract}

Keywords: mortality, life-course, birth weight, fetal development, Sweden.

Abbreviations: CI, confidence interval; OR, odd ratio; LBW, low birthweight; SGA, small-for-gestational age; LGA, large-for-gestational age; AGA, adequate birthweightfor-gestational age; pyar, person-years 


\section{$\underline{\text { Introduction }}$}

Birthweight is both a maternal reproductive health outcome and a neonatal health indicator, and has been shown to be associated with several outcomes later in life. Birthweight (mainly in the form of low birthweight (LBW)) has been associated with intellectual impairment ${ }^{1,2}$, and with specific morbidities including obesity, coronary heart disease, type-2 diabetes, hypertension, and metabolic syndrome, among others ${ }^{3-6}$. Moreover, extensive literature shows an association between birthweight and mortality; LBW individuals have a higher probability of dying earlier compared to those with normal birthweight ${ }^{7-13}$. The fact that this association is not confined to early life mortality ${ }^{7,11,12,14,15}$ but is also observed in adulthood ${ }^{7,8,11-13,16,17}$ suggests that the earlylife environment may alter susceptibility to develop a disease across the life-course ${ }^{18}$. These findings are interpreted as evidence of the 'Developmental Origins of Health and Diseases' (DOHaD) ${ }^{19}$.

Despite the abundant evidence showing an association between birthweight and mortality, there still remain some important knowledge gaps and questions. For example, due to data limitations, most studies only explore associations using very wide age intervals $^{13,17,20}$ and with few exceptions ${ }^{7,13,17}$ have been conducted in young cohorts $^{9,11,12,20}$. For example, a recent meta-analysis ${ }^{8}$ concluded that birthweight appears to be a predictor of all-cause mortality at fairly young to middle adult ages, but was unable to examine whether this was also the case at older ages because of a lack of studies.

The potential confounding role of social determinants is another aspect requiring further investigation $^{21}$. Birthweight is considered to be a result of both biological and social determinants that interact in the womb when human nature is particularly "plastic" (sensitive) to environmental stimuli ${ }^{22,23}$. Thus, early-life socioeconomic characteristics may be associated with a higher risk of mortality through "fetal programming" 3 or other mechanisms associated with unequal opportunities and material disadvantages ${ }^{24}$. Very few studies, ${ }^{16}$ however, explicitly examine the contribution (as confounders or modifiers) of early-life social characteristics to the association between perinatal health and allcause mortality. In addition, although some studies ${ }^{12,16}$ adjust for social characteristics in childhood, such information might be incomplete leading to residual confounding. This relates to a broader challenge in population-based studies, namely to establish how far associations between perinatal health and mortality reflect confounding by unmeasured (or mismeasured) environmental or genetic characteristics related to the mother. A previous study estimated that $49 \%$ of the total individual variance in birthweight was explained by maternal-level characteristics, ${ }^{25}$ and attempting to minimise maternal confounding is therefore crucial. One way to deal with such confounding, and to strengthen the evidence for causality, is to compare siblings with discordant exposures (e.g., one was born low birthweight and the other was not).

Our study aims to address these gaps by studying the association between perinatal health indicators (gestational age, absolute and relative birthweight-for-gestational age) and allcause mortality during different age intervals in cohorts followed between 1915 and 
2009. This study further aims to assess the contribution of socioeconomic factors to these relationships, and use sibling analyses to investigate the potential contribution of unmeasured family-level confounding.

\section{Methods}

\section{Study population}

Our study is based on the first generation of the Uppsala Birth Cohort Multigenerational Study (UBCoS Multigen) (www.chess.su.se/ubcosmg/), which comprises all live births at Uppsala University Hospital between 1915 and 1929. ${ }^{26,27}$ Follow-up started from birth and continued until death, emigration or December 31, 2009, whichever was earliest. From a total of 14,192 live births, we excluded multiple births $(n=444)$, as their growth rate is reduced in the final trimester. ${ }^{28}$ We additionally excluded $6 \%$ of singleton births because of missing data on birthweight $(n=101)$, gestational age $(n=398)$, parity $(n=1)$, maternal age $(n=1)$, marital status $(n=29)$ and parental occupation $(n=370)$. We further excluded subjects if the recorded gestational age was below the biological viability threshold of 22 weeks $(n=2)$ or if the individual could not be traced after their birth $(\mathrm{n}=282)$. The total sample size was 12,564 subjects ( $89 \%$ of all live births) of whom $53 \%$ were males.

\section{Explanatory variables}

Table 1 presents the exposure variables of interest. Birthweight was classified into lower weight $(<3000 \mathrm{~g})$, normal weight (3000-3999 g) and macrosomia ( $\geq 4000 \mathrm{~g})$. Gestational age was categorized into preterm ( $<37$ gestational weeks), term $(37-41$ weeks) and postterm ( $\geq 42$ weeks). Relative birthweight (birthweight for gestational age) was calculated by standardising birthweight on a week-by-week basis, standardising separately for males and females. We used the means and standard deviations observed in UBCoS for the 13,599 members of the total cohort who were born at 30 or more completed weeks (i.e. an internal reference). For the 86 children born at 22-29 weeks we used external reference data ${ }^{29}$ adjusted for birth weight distributions observed within our cohort; full details available in the Supplementary Material. We then categorized birthweight for gestational age using standard percentile thresholds: infants below the $10^{\text {th }}$ percentile were "small-for-gestational age" (SGA), infants between the $10^{\text {th }}$ and the $90^{\text {th }}$ percentiles were "adequate-birthweight-for gestational age" (AGA), and infants above the $90^{\text {th }}$ percentile were "large-for-gestational age" (LGA). Family socioeconomic information was derived based on the Swedish socio-economic classification scheme, ${ }^{30}$ using father's occupation if recorded $(80 \%)$ or otherwise using mother's occupation $(20 \%))^{31}$ Occupational social class was categorized into higher and intermediate non-manual workers (including e.g. physicians, academic professions, teachers and engineers), entrepreneurs and farmers, lower non-manual, skilled manuals, unskilled manuals (manufacturing sector), unskilled manuals (service sector) and house-daughters (women who live with their parents at the moment of giving birth). Marital status was classified into two groups: married and single/divorced/widowed. Mother's age was categorized 
into four groups $\leq 24,25-29,30-34$ and 35+ years old. Parity was assessed as 1, 2, 3, and $\geq 4$, and birth years into three groups: 1915-1919, 1920-1924 and 1925-1929.

\section{Statistical Analysis}

We fitted Cox regression models defined on the age time scale. Because of expected time varying effects of the exposures of interest (absolute and relative birthweight, and gestational age) we allowed for interactions between the exposures and categorised age, with bands: <1, 1-4, 5-29, 30-44, 45-59, 60-69, 70-79 and 80+ years. These age bands follow the categorization used by the World Health Organisation, ${ }^{32}$ with two modifications. First, we disaggregated the first age interval (0-4) into two groups in order to investigate infant mortality $(<1)$ and child mortality (1 to 4$)$ separately. Second, to increase power, we collapsed the central age groups (5-14 and 15-29) which contained only small number of deaths and there was no evidence of heterogeneity between these age groups. From these Cox regression models we derived estimates of age-band specific hazard ratios of overall mortality, with $95 \%$ confidence intervals derived from robust standard errors to account for within family correlations. We performed random effects meta-analysis to estimate 1-squared statistics, and used this to test whether there was evidence of heterogeneity between the effects estimated at different ages.

To assess the extent to which family socioeconomic characteristics confounded the association between each exposure and mortality, we first estimated models with minimal adjustment (adjusted for sex, birth year and mutual adjustment for birthweight and gestational age); secondly we included maternal age and parity; and finally we included socioeconomic information (i.e., parental socioeconomic status and marital status). We also assessed whether the associations between perinatal variables and mortality were modified by socioeconomic status or gender. The significance of exposure effects and their interactions with age, gender and socio-economic status were assessed using Wald tests ${ }^{33}$.

In order to explore whether unobserved maternal-level confounding affected the results, we additionally conducted within-family (sibling) analyses by comparing outcomes of siblings born to the same mother (i.e., 5,843 (47\%) newborns nested in 2,323 mothers). This approach was originally designed ${ }^{34}$ and used in previous studies ${ }^{35}$ for linear predictor variables. This paper uses an extension for binary predictor variables. To do this we first assigned each cohort member a binary variable for a predictor in question, e.g. 0 for 'not SGA' and 1 for 'SGA'. We then created for each subject a 'between-mother' variable representing the average across all the mother's offspring (e.g. the proportion of their children who were SGA) and a 'within-mother' variable representing the departure of each individual from that mean (e.g. the cohort member's own SGA status minus the mother's average: equations in the Supplementary Material). We then used Wald tests to compare the effect sizes of these two variables when entered simultaneously into Cox regression analyses: if they differed significantly we interpreted this as evidence of residual maternal-level confounding ${ }^{34}$. If associations were entirely the product of such confounding, one would expect the within-mother effect to be (i) significantly weaker than the between-mother effect (in the case of positive confounding) or stronger than the 
between mother (if the confounding is driven by negative confounding) and (ii) not significantly different from zero. When comparing the between and within mother effect sizes we adjusted for sex, year of birth, mother's age, parity, and other birth information in order to control for those characteristics which may differ between siblings (i.e., temporal confounding). ${ }^{36}$

We present descriptive statistics stratified by gender, but pool males and females in our main analyses as there was never convincing evidence of interactions between birth outcomes and gender with respect to mortality were not significant (all $p \geq 0.15$ in tests for interaction in the total sample; all $\mathrm{p} \geq 0.04$ in tests for interaction in specific age strata). Combining the genders also had the advantage of increasing statistical power.

All analyses were performed using Stata, version 13, software (StatCorp, LP, College Station, Texas). This study was approved by the Regional Ethics Committee in Stockholm.

\section{$\underline{\text { Results }}$}

Table 1 shows the distribution of the number of subjects at risk, deaths from all causes, and death rates per 1000 person-years (pyar) by different levels of the explanatory variables. As expected, higher death rates were observed among lower birthweight and SGA subjects $(\approx 11 / 1000$ pyar) as well as among preterm subjects $(13 / 1000$ pyar). The death rate was higher among males than females (11/1000 pyar vs $9 / 1000$ pyar) and it progressively increased with parity. Offspring from mothers younger than 24 and older than 35 had higher death rates $(\approx 10 / 1000$ pyar) than those at central ages. As expected, there was a higher death rate among offspring of unmarried mothers (12/1000 pyar) and of mothers with low socioeconomic status $(\approx 10 / 1000$ pyar). Figure 1 shows lower survival curves for lower birthweight, SGA, and preterm subjects in all ages. Preterm was the exposure with the highest survival differences relative to the reference category. 
Table 1. Characteristics of the analyzed population, number and proportion of deaths, and mortality rates. Uppsala Birth Cohort Multigenerational study, 1915-1929 (N=12,564)

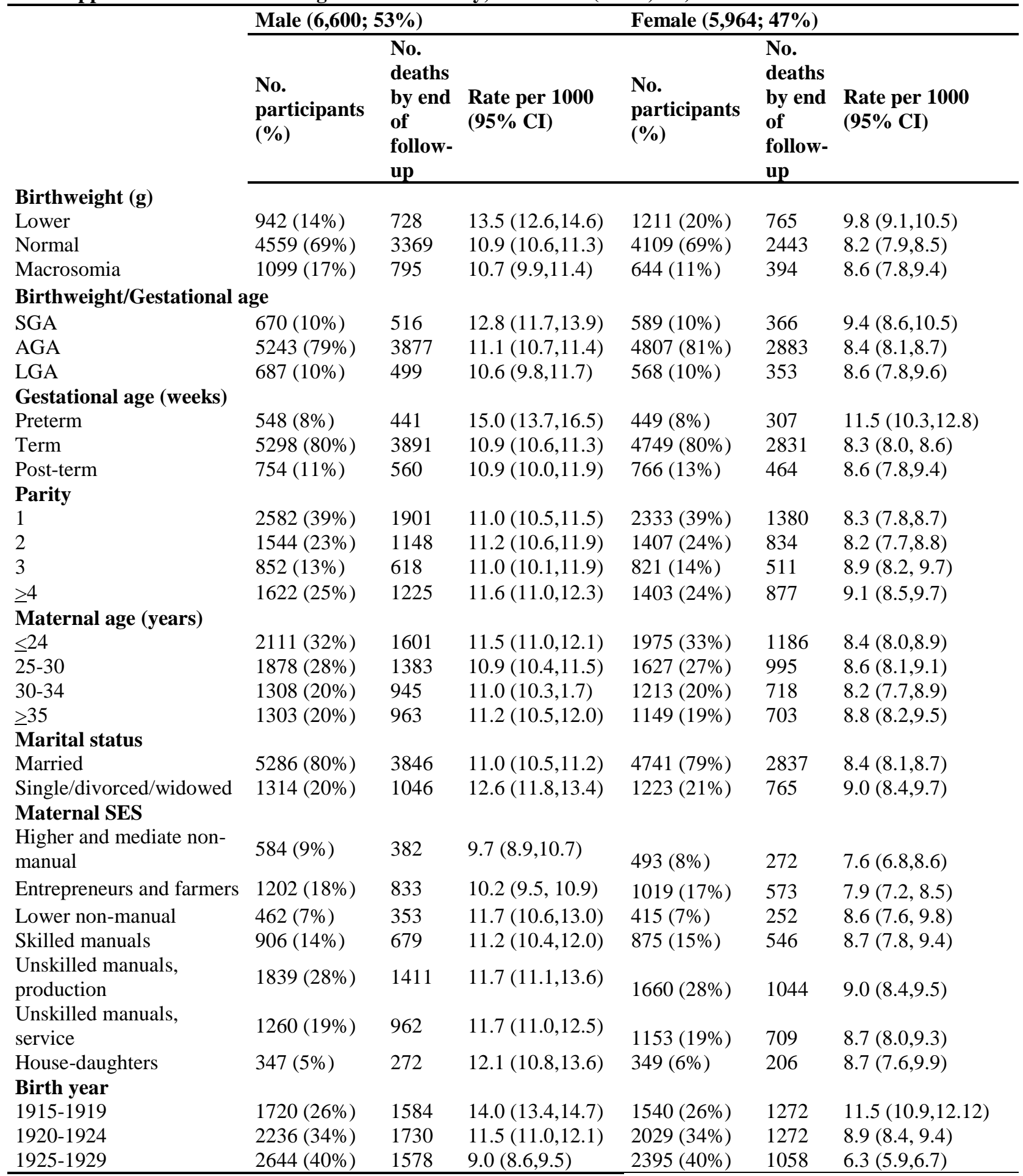

Abbreviations: SES: Socio-economic status 
Fig. 1. Kaplan-Meier survival curves by absolute (a), relative(b) birth weight and gestational age (c) stratified by gender.
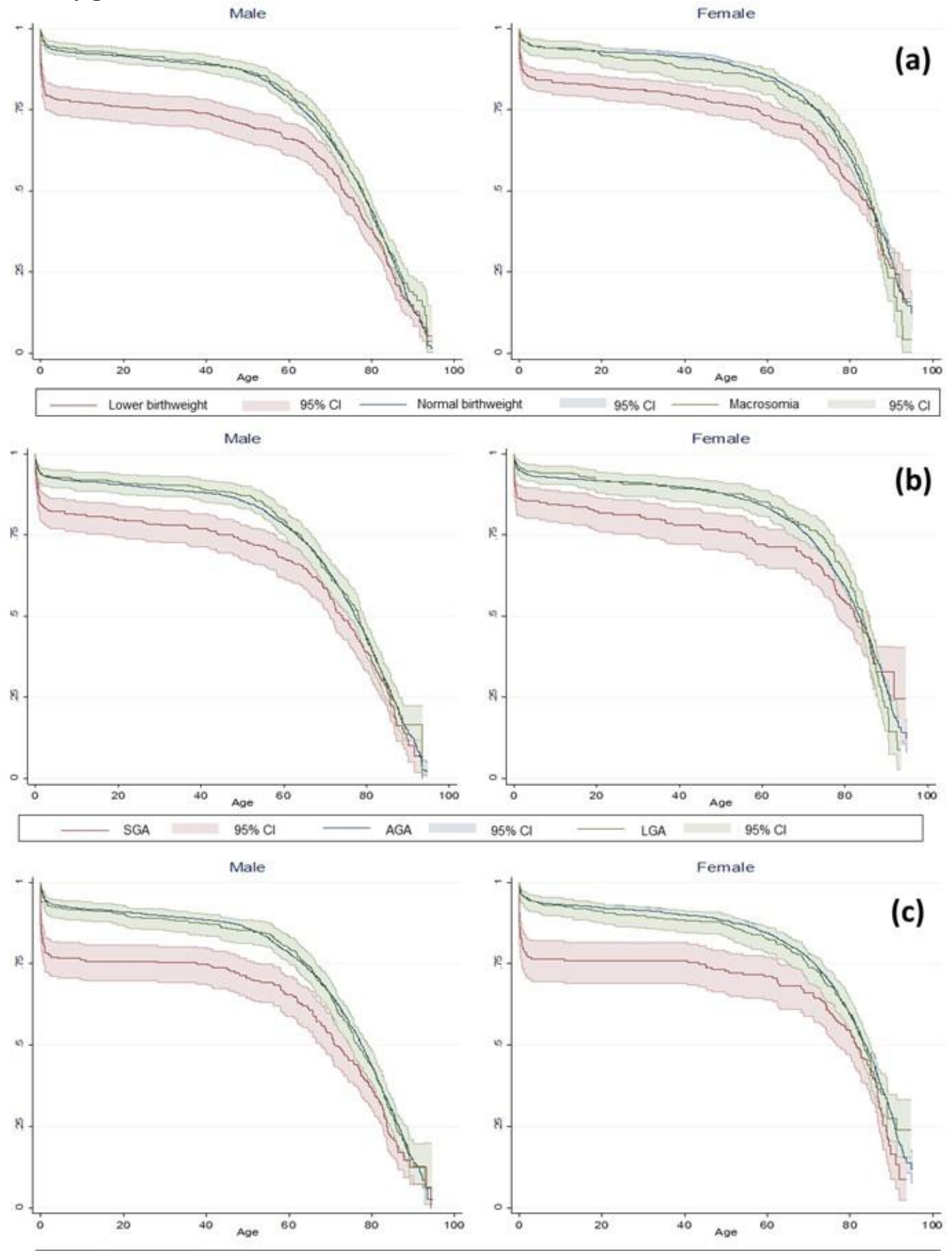

\begin{tabular}{|lllllll}
\hline & Preterm & $95 \% \mathrm{Cl}$ & $\longrightarrow$ & Term & $95 \% \mathrm{Cl}$ & \\
\hline
\end{tabular}


Table 2 shows the estimated associations between absolute birthweight and all-cause mortality at different ages with different levels of adjustment. Lower birthweight offspring had a higher rate of death than those with normal weight overall, but there was strong evidence that the strength of this effect differed according to age group $(\mathrm{p}<0.001$ for heterogeneity). Specifically, the effect was largest in the first year of life and then continued up to 44 years of age (although it did not reach significance at the interval 1-4 years, plausibly because of low statistical power). These results were similar after partial and further adjustment for maternal and family characteristics. There was also never evidence in the sibling analysis that the between-mother and within-mother effect size differed for those age groups that show a higher risk (Fig. 2). In other words, among offspring of the same mother, the risk of increased mortality was specific to the infant born at lower birthweight and not to his or her siblings born at a normal birth weight. This provides evidence that the effects observed in Table 2 do not include residual maternal-level confounding, and supports the interpretation that lower birthweight has a causal effect on all-cause mortality.

Table 2. Survival analysis (Hazard Ratios, 95\% Confidence Intervals) for absolute birthweight (ref. 3000-3999 gr) and all-cause mortality by age intervals and level of confounding control.

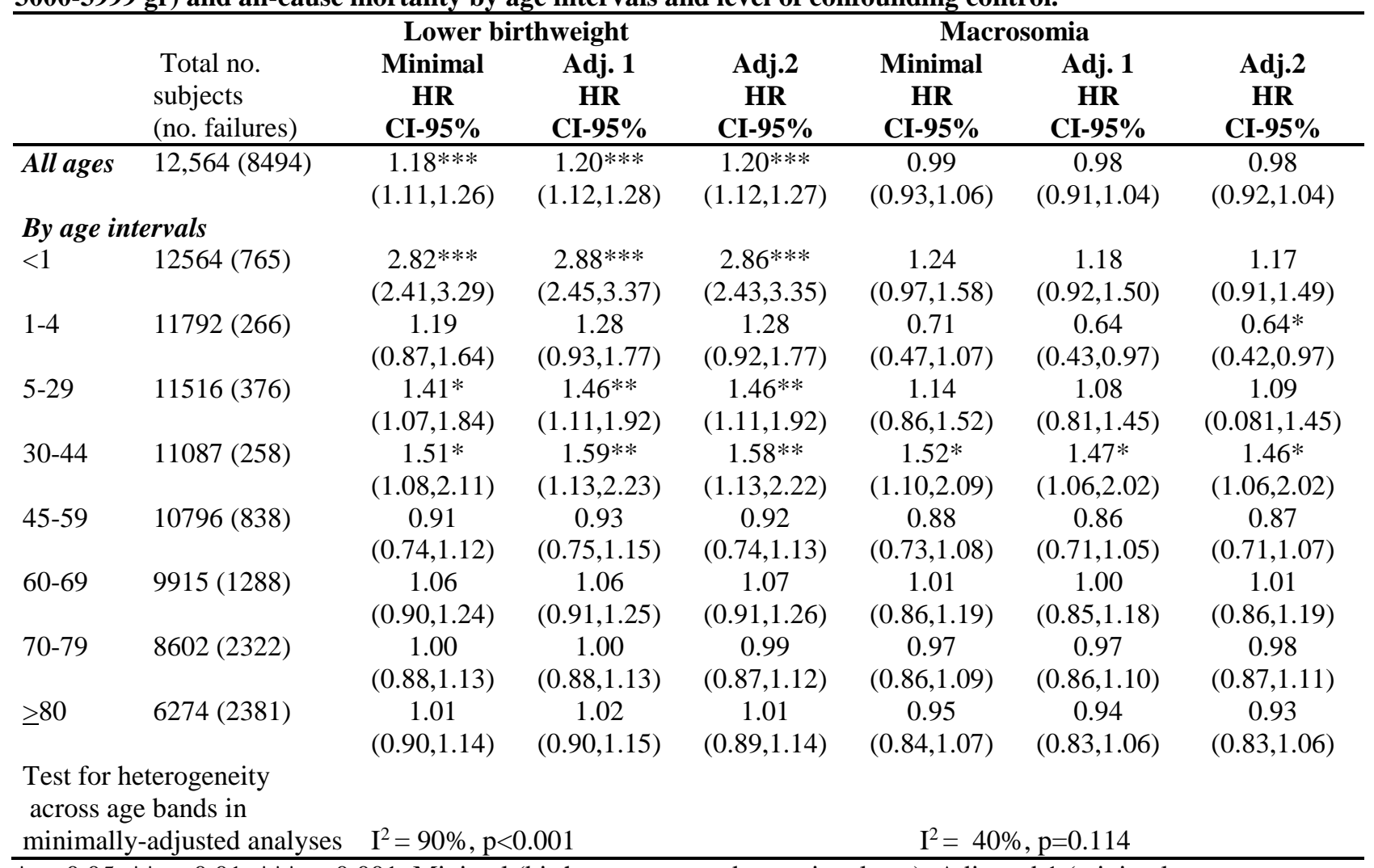

$* \mathrm{p}<0.05, * * \mathrm{p}<0.01, * * * \mathrm{p}<0.001$. Minimal (birth year, sex, and gestational age), Adjusted 1 (minimal + parity and maternal age), Adjusted 2 (Adj.1 + marital status and socioeconomic status).

Abbreviations: Hazard ratios (HR), CI (Confidence Intervals). 
Fig. 2. Sibling analysis for the effect of lower v. normal birth weight by age band. Log, logarithm; HR, hazard ratio

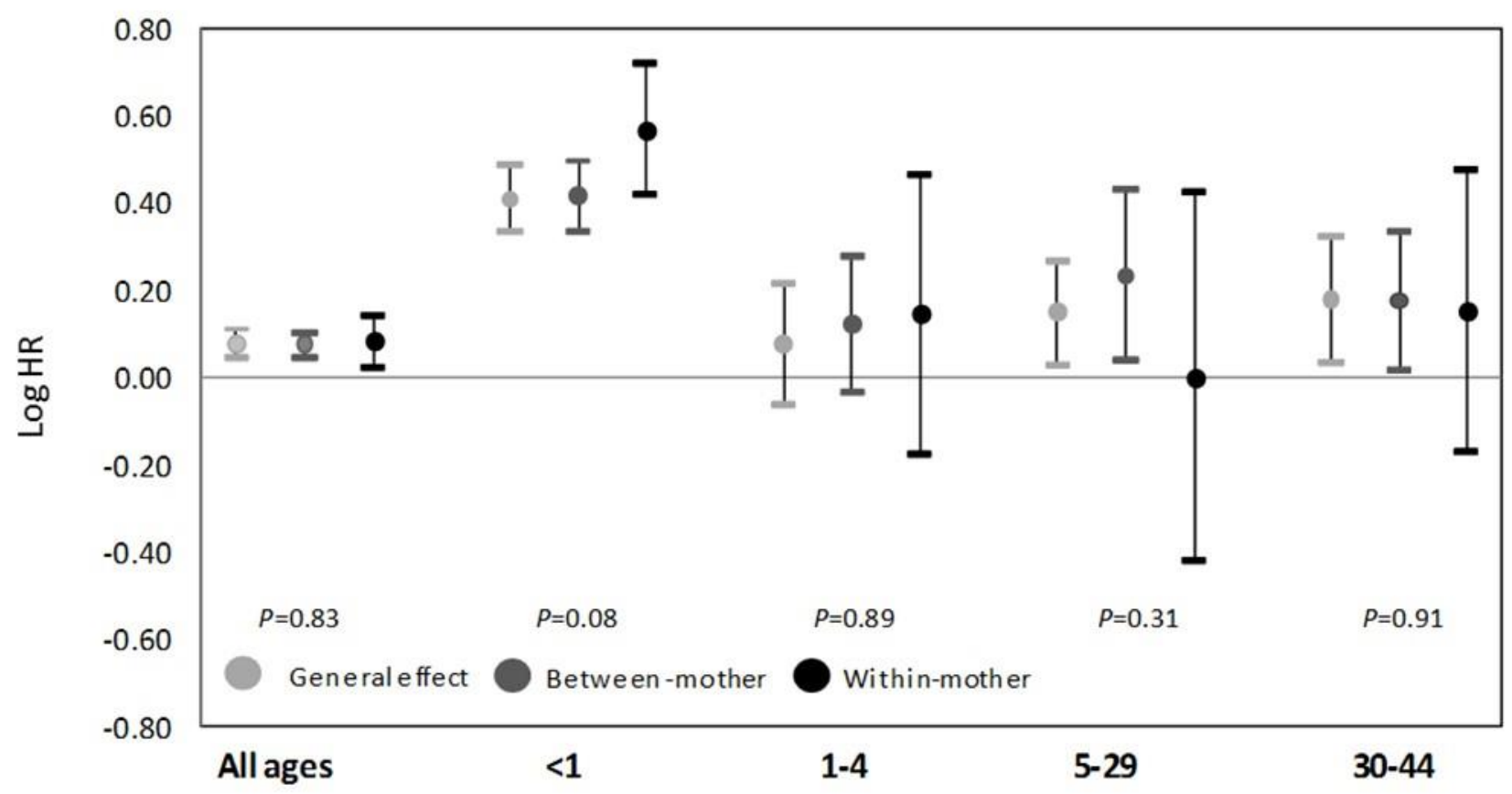

mortality at ditterent ages with ditterent levels of adjustment. I nere was strong evidence of heterogeneity by age group in the effects of SGA $(\mathrm{p}<0.001$ for heterogeneity). Compared to AGA subjects, SGA subjects showed a trend towards a higher mortality rate up to 44 years of age, although the differences were larger during the first year of life, and were only statistically significant during the first year of life. The sibling analysis indicated that there was no evidence that residual maternal-level confounding explained the higher rate of mortality among SGA subjects at all these ages (Fig. 3). 
Table 3. Survival analysis for relative birthweight (reference AGA) and all-cause mortality by age intervals.

\begin{tabular}{|c|c|c|c|c|c|c|c|}
\hline & $\begin{array}{l}\text { Total no. } \\
\text { subjects } \\
\text { (no. failures) }\end{array}$ & $\begin{array}{c}\text { SGA } \\
\text { Minimal } \\
\text { HR } \\
\text { CI-95\% }\end{array}$ & $\begin{array}{c}\text { Adj. } 1 \\
\text { HR } \\
\text { CI-95\% }\end{array}$ & $\begin{array}{c}\text { Adj.2 } \\
\text { HR } \\
\text { CI-95\% }\end{array}$ & $\begin{array}{c}\text { LGA } \\
\text { Minimal } \\
\text { HR } \\
\text { CI-95\% }\end{array}$ & $\begin{array}{c}\text { Adj. } 1 \\
\text { HR } \\
\text { CI-95\% }\end{array}$ & $\begin{array}{c}\text { Adj.2 } \\
\text { HR } \\
\text { CI-95\% }\end{array}$ \\
\hline All ages & $12,564(8903)$ & $\begin{array}{c}1.19 * * * \\
(1.11,1.29)\end{array}$ & $\begin{array}{c}1.21 * * * \\
(1.12,1.30)\end{array}$ & $\begin{array}{c}1.20 * * * \\
(1.12,1.30)\end{array}$ & $\begin{array}{c}0.96 \\
(0.90,1.03)\end{array}$ & $\begin{array}{c}0.94 \\
(0.88,1.01)\end{array}$ & $\begin{array}{c}0.95 \\
(0.88,1.02)\end{array}$ \\
\hline \multicolumn{8}{|c|}{ By age intervals } \\
\hline$<1$ & 12564 (765) & $\begin{array}{c}2.56 * * * \\
(2.15,3.06)\end{array}$ & $\begin{array}{c}2.60 * * * \\
(2.17,3.11)\end{array}$ & $\begin{array}{c}2.58 * * * \\
(2.15,3.08)\end{array}$ & $\begin{array}{c}0.92 \\
(0.70,1.19)\end{array}$ & $\begin{array}{c}0.88 \\
(0.67,1.14)\end{array}$ & $\begin{array}{c}0.87 \\
(0.67,1.13)\end{array}$ \\
\hline $1-4$ & $11792(266)$ & $\begin{array}{c}1.26 \\
(0.87,1.84)\end{array}$ & $\begin{array}{c}1.35 \\
(0.93,1.97)\end{array}$ & $\begin{array}{c}1.35 \\
(0.92,1.97)\end{array}$ & $\begin{array}{c}0.62 \\
(0.38,1.01)\end{array}$ & $\begin{array}{c}0.56^{*} \\
(0.34,0.92)\end{array}$ & $\begin{array}{c}0.56^{*} \\
(0.34,0.92)\end{array}$ \\
\hline $5-29$ & $11516(376)$ & $\begin{array}{c}1.20 \\
(0.87,1.67)\end{array}$ & $\begin{array}{c}1.25 \\
(0.90,1.74)\end{array}$ & $\begin{array}{c}1.25 \\
(0.90,1.74)\end{array}$ & $\begin{array}{c}0.95 \\
(0.67,1.34)\end{array}$ & $\begin{array}{c}0.90 \\
(0.63,1.28)\end{array}$ & $\begin{array}{c}0.90 \\
(0.63,1.28)\end{array}$ \\
\hline $30-44$ & 11087 (258) & $\begin{array}{c}1.31 \\
(0.89,1.93)\end{array}$ & $\begin{array}{c}1.39 \\
(0.94,2.04)\end{array}$ & $\begin{array}{c}1.39 \\
(0.94,2.05)\end{array}$ & $\begin{array}{c}1.10 \\
(0.74,1.63)\end{array}$ & $\begin{array}{c}1.05 \\
(0.70,1.56)\end{array}$ & $\begin{array}{c}1.05 \\
(0.70,1.57)\end{array}$ \\
\hline $45-59$ & $10796(838)$ & $\begin{array}{c}1.01 \\
(0.80,1.28)\end{array}$ & $\begin{array}{c}1.03 \\
(0.81,1.31)\end{array}$ & $\begin{array}{c}1.02 \\
(0.80,1.30)\end{array}$ & $\begin{array}{c}0.91 \\
(0.73,1.15)\end{array}$ & $\begin{array}{c}0.89 \\
(0.71,1.12)\end{array}$ & $\begin{array}{c}0.90 \\
(0.71,1.13)\end{array}$ \\
\hline $60-69$ & 9915 (1288) & $\begin{array}{c}1.03 \\
(0.86,1.25)\end{array}$ & $\begin{array}{c}1.04 \\
(0.86,1.25)\end{array}$ & $\begin{array}{c}1.04 \\
(0.86,1.26)\end{array}$ & $\begin{array}{c}1.01 \\
(0.85,1.21)\end{array}$ & $\begin{array}{c}1.00 \\
(0.83,1.20)\end{array}$ & $\begin{array}{c}1.01 \\
(0.84,1.22)\end{array}$ \\
\hline $70-79$ & $8602(2322)$ & $\begin{array}{c}1.01 \\
(0.88,1.17)\end{array}$ & $\begin{array}{c}1.02 \\
(0.88,1.17)\end{array}$ & $\begin{array}{c}1.00 \\
(0.87,1.15)\end{array}$ & $\begin{array}{c}0.91 \\
(0.79,1.05)\end{array}$ & $\begin{array}{c}0.91 \\
(0.79,1.05)\end{array}$ & $\begin{array}{c}0.92 \\
(0.80,1.06)\end{array}$ \\
\hline$\geq 80$ & $6274(2381)$ & $\begin{array}{c}1.10 \\
(0.95,1.26)\end{array}$ & $\begin{array}{c}1.10 \\
(0.95,1.27)\end{array}$ & $\begin{array}{c}1.09 \\
(0.94,1.26)\end{array}$ & $\begin{array}{c}1.05 \\
(0.92,1.19)\end{array}$ & $\begin{array}{c}1.04 \\
(0.91,1.18)\end{array}$ & $\begin{array}{c}1.04 \\
(0.91,1.18)\end{array}$ \\
\hline $\begin{array}{l}\text { Test for } \\
\text { across a } \\
\text { minimal }\end{array}$ & $\begin{array}{l}\text { terogeneity } \\
\text { bands in } \\
\text { adjusted analyses }\end{array}$ & $\mathrm{I}^{2}=84 \%$ & $\mathrm{p}<0.001$ & & $\mathrm{I}^{2}=9 \%$, & $\mathrm{p}=0.357$ & \\
\hline
\end{tabular}

$* \mathrm{p}<0.05, * * \mathrm{p}<0.01, * * * \mathrm{p}<0.001$. Minimal (birth year, sex and gestational age), adjusted 1 (minimal + parity and maternal age), adjusted 2 (adj.1 + marital status and socioeconomic status).

Abbreviations: Hazard ratios (HR), CI (Confidence Intervals), Adequate birthweight-for-Gestational-Age (AGA), Small-for-Gestational-Age (SGA), Large-for-Gestational-Age (LGA). 
Fig. 3. Sibling analysis for the effect of small age v. adequate for-gestational age by age band. Log, logarithm; HR, hazard ratio.

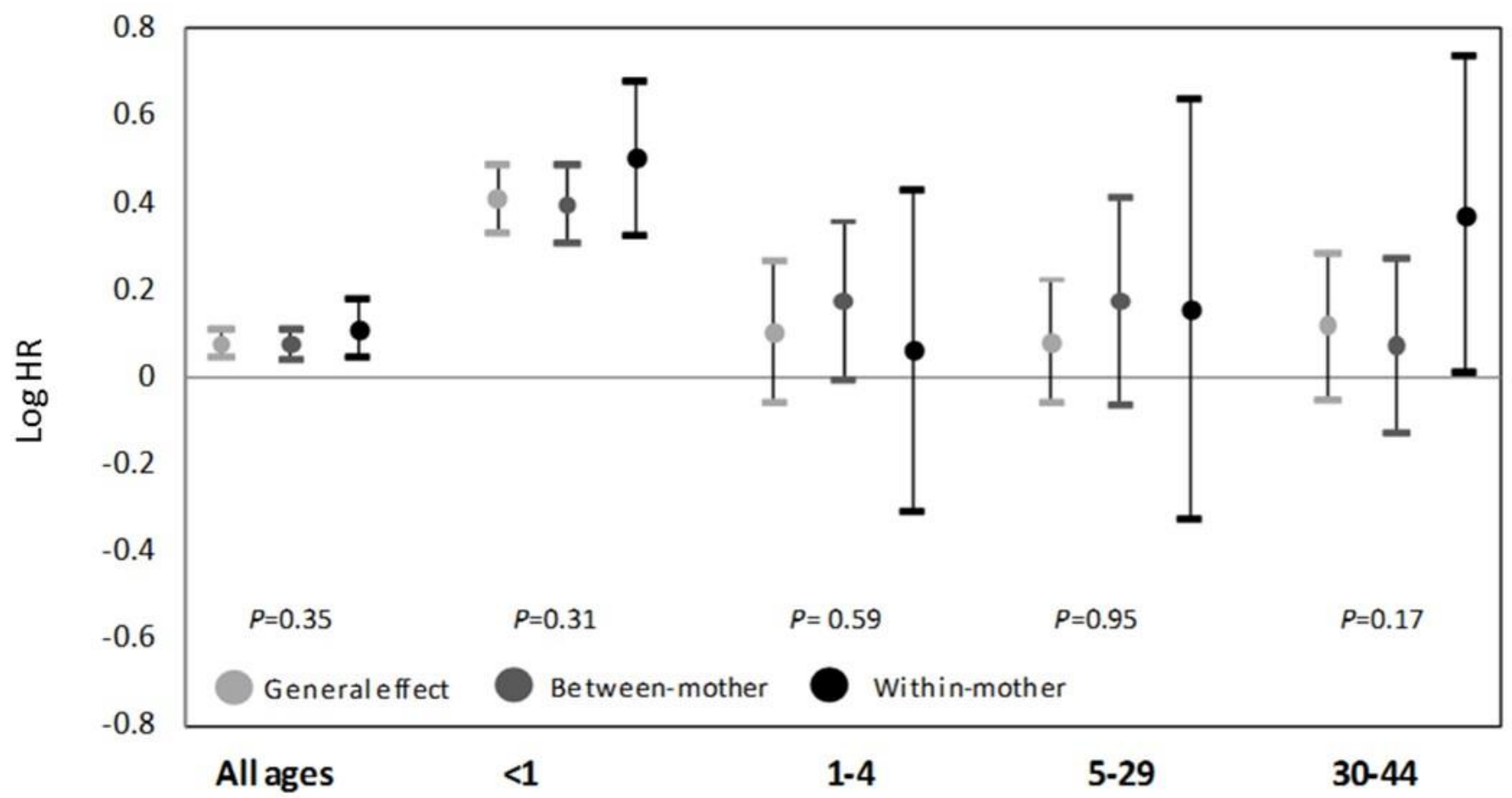


Table 4. Survival analysis for gestational age (reference= term births) and all-cause mortality by age group.

\begin{tabular}{|c|c|c|c|c|c|c|c|}
\hline & $\begin{array}{l}\text { Total no. } \\
\text { subjects } \\
\text { (no. failures) }\end{array}$ & $\begin{array}{c}\text { Preterm } \\
\text { Minimal } \\
\text { HR } \\
\text { CI-95\% }\end{array}$ & $\begin{array}{c}\text { Adj.1 } \\
\text { HR } \\
\text { CI-95\% }\end{array}$ & $\begin{array}{c}\text { Adj.2 } \\
\text { HR } \\
\text { CI-95\% }\end{array}$ & $\begin{array}{c}\text { Post-term } \\
\text { Minimal } \\
\text { HR } \\
\text { CI-95\% }\end{array}$ & $\begin{array}{c}\text { Adj.1 } \\
\text { HR } \\
\text { CI-95\% }\end{array}$ & $\begin{array}{c}\text { Adj.2 } \\
\text { HR } \\
\text { CI-95\% }\end{array}$ \\
\hline All ages & $12,564(8903)$ & $\begin{array}{c}1.31 * * * \\
(1.20,1.43)\end{array}$ & $\begin{array}{c}1.31 * * * \\
(1.20,1.43)\end{array}$ & $\begin{array}{c}1.28 * * * \\
(1.17,1.40)\end{array}$ & $\begin{array}{c}1.06 \\
(0.99,1.13)\end{array}$ & $\begin{array}{c}1.05 \\
(0.99,1.12)\end{array}$ & $\begin{array}{c}1.04 \\
(0.97,1.11)\end{array}$ \\
\hline \multicolumn{8}{|c|}{ By age intervals } \\
\hline$<1$ & $12564(765)$ & $\begin{array}{c}3.13 * * * \\
(2.64,3.72)\end{array}$ & $\begin{array}{c}3.10^{* * *} \\
(2.61,3.68)\end{array}$ & $\begin{array}{c}3.04 * * * \\
(2.56,3.61)\end{array}$ & $\begin{array}{c}1.09 \\
(0.85,1.39)\end{array}$ & $\begin{array}{c}1.07 \\
(0.84,1.38)\end{array}$ & $\begin{array}{c}1.06 \\
(0.83,1.36)\end{array}$ \\
\hline $1-4$ & 11792 (266) & $\begin{array}{c}1.38 \\
(0.91,2.09)\end{array}$ & $\begin{array}{c}1.37 \\
(0.91,2.08)\end{array}$ & $\begin{array}{c}1.33 \\
(0.88,2.02)\end{array}$ & $\begin{array}{c}1.04 \\
(0.71,1.52)\end{array}$ & $\begin{array}{c}1.01 \\
(0.69,1.47)\end{array}$ & $\begin{array}{c}1.00 \\
(0.68,1.46)\end{array}$ \\
\hline $5-29$ & $11516(376)$ & $\begin{array}{c}0.90 \\
(0.59,1.36)\end{array}$ & $\begin{array}{c}0.89 \\
(0.58,1.36)\end{array}$ & $\begin{array}{c}0.88 \\
(0.58,1.34)\end{array}$ & $\begin{array}{c}1.02 \\
(0.75,1.39)\end{array}$ & $\begin{array}{c}1.02 \\
(0.74,1.38)\end{array}$ & $\begin{array}{c}1.01 \\
(0.74,1.37)\end{array}$ \\
\hline $30-44$ & 11087 (258) & $\begin{array}{c}0.90 \\
(0.53,1.51)\end{array}$ & $\begin{array}{c}0.89 \\
(0.53,1.49)\end{array}$ & $\begin{array}{c}0.88 \\
(0.52,1.48)\end{array}$ & $\begin{array}{c}1.07 \\
(0.75,1.53)\end{array}$ & $\begin{array}{c}1.06 \\
(0.74,1.52)\end{array}$ & $\begin{array}{c}1.05 \\
(0.73,1.50)\end{array}$ \\
\hline $45-59$ & $10796(838)$ & $\begin{array}{c}1.16 \\
(0.88,1.52)\end{array}$ & $\begin{array}{c}1.15 \\
(0.88,1.51)\end{array}$ & $\begin{array}{c}1.12 \\
(0.86,1.47)\end{array}$ & $\begin{array}{c}1.01 \\
(0.82,1.25)\end{array}$ & $\begin{array}{c}1.00 \\
(0.81,1.24)\end{array}$ & $\begin{array}{c}0.99 \\
(0.80,1.23)\end{array}$ \\
\hline $60-69$ & 9915 (1288) & $\begin{array}{c}1.22 \\
(0.98,1.51)\end{array}$ & $\begin{array}{c}1.21 \\
(0.98,1.50)\end{array}$ & $\begin{array}{c}1.19 \\
(0.96,1.48)\end{array}$ & $\begin{array}{c}1.03 \\
(0.86,1.22)\end{array}$ & $\begin{array}{c}1.02 \\
(0.86,1.21)\end{array}$ & $\begin{array}{c}1.01 \\
(0.85,1.20)\end{array}$ \\
\hline $70-79$ & 8602 (2322) & $\begin{array}{c}0.90 \\
(0.74,1.08)\end{array}$ & $\begin{array}{c}0.89 \\
(0.74,1.08)\end{array}$ & $\begin{array}{c}0.88 \\
(0.73,1.06)\end{array}$ & $\begin{array}{c}1.08 \\
(0.96,1.22)\end{array}$ & $\begin{array}{c}1.08 \\
(0.95 .1 .22)\end{array}$ & $\begin{array}{c}1.06 \\
(0.94,1.20)\end{array}$ \\
\hline$\geq 80$ & $6274(2381)$ & $\begin{array}{c}1.17 \\
(1.00 .1 .38)\end{array}$ & $\begin{array}{c}1.17 \\
(1.00,1.38)\end{array}$ & $\begin{array}{c}1.16 \\
(0.98,1.36)\end{array}$ & $\begin{array}{c}1.07 \\
(0.94,1.21)\end{array}$ & $\begin{array}{c}1.06 \\
(0.94,1.21)\end{array}$ & $\begin{array}{c}1.05 \\
(0.93,1.19)\end{array}$ \\
\hline $\begin{array}{l}\text { Test for } h \\
\text { across ag } \\
\text { minimally }\end{array}$ & $\begin{array}{l}\text { terogeneity } \\
\text { bands in } \\
\text {-adjusted analyses }\end{array}$ & $\mathrm{I}^{2}=89 \%$ & $\mathrm{p}<0.001$ & & $\mathrm{I}^{2}=0$ & $\mathrm{p}=0.999$ & \\
\hline
\end{tabular}


Fig. 4. Sibling analysis for preterm v. term by age band. Log, logarithm; HR, hazard ratio.

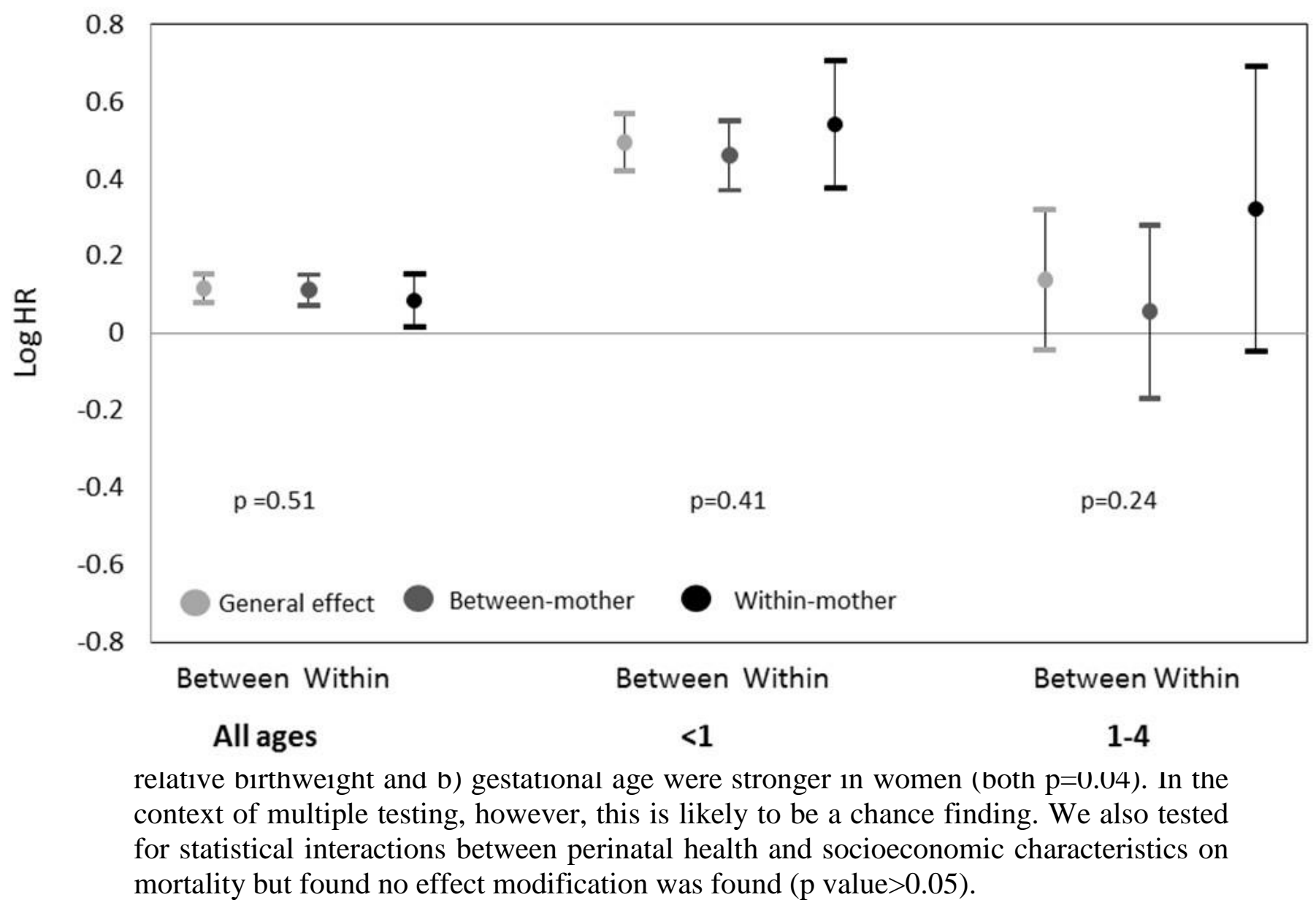

\section{$\underline{\text { Discussion }}$}

\section{Summary of results}

This study provides evidence that both absolutely and relatively small newborns, as well as those born preterm, have a higher risk of mortality. However, these associations significantly differ by age intervals and according to the measure under scrutiny. Thus, while preterm birth is associated to a higher rate of all-cause mortality up to 4 years of age, lower birthweight and SGA appear to be associated with a higher mortality rate up until 44 years of age. We did not find evidence that observable early-life socioeconomic disadvantage explains or modifies the association between perinatal health and mortality. Our sibling analyses support this conclusion, and also indicate that the observed effects are not likely to reflect residual confounding at the maternal level.

\section{Consistency with other research}

Like many other studies, ${ }^{7-9,11-14}$ we found that birthweight was associated with all-cause mortality. Our results support a previous hypothesis that birthweight specifically predicts 
mortality at fairly young to middle adult ages, rather than at older ages, ${ }^{8}$ since lower birthweight and SGA was associated to mortality up to 44 years of age. The effect observed in younger adult ages is consistent with one previous study which found a higher risk of all-cause mortality between $15-49$ years ${ }^{16}$.

In line with another Swedish study carried out in a more contemporary context (Swedish men and women born 1973-2008) ${ }^{20}$, we did not find a U-shaped association between birthweight and all-cause mortality at all ages - that is, we did not find a higher overall mortality rate among macrosomic subjects. There was some indication of a U-shaped association between birthweight and mortality in the age interval 30-44 which is consistent with another study (using the Danish School-based cohort, 1936-1979) ${ }^{9}$, that found similar evidence in a larger age window 25-68. Our finding of an effect at age 3044 should, however, be interpreted with caution as the test for heterogeneity suggests that it may simply be due to chance.

The association between preterm birth and mortality in infancy and early childhood (up to 4 years of age) is consistent with a previous study conducted in Norway ${ }^{37}$, although unlike that study we did not find any effect for an effect of post-term birth in these age bands.

Like previous studies ${ }^{9,20,38}$, we do not present analyses stratified by gender, because we did not find evidence of effect modification after testing for interactions of perinatal health and gender in their effect on mortality. Finally, in accordance with earlier studies ${ }^{12,16,20}$ the inclusion of observable early-life socioeconomic characteristics does not explain the association between perinatal health and all-cause mortality.

\section{Originality}

Our study is unique in assessing the association between birthweight and all-cause mortality with a focus on specific age intervals. Moreover, we investigated the potential contribution of unobserved familial confounding using a sibling design. Although one previous study ${ }^{20}$ assessed this association looking for evidence of family-level confounding, the latter used fixed-effect models while we applies an approach that allowed formal statistical comparisons of between-mother versus within-mother effects. Our study is also original in that it focuses on the specific contribution of socioeconomic circumstances, not only as a possible confounder, but also as a modifier of the association between birthweight and all-cause mortality.

\section{Strengths and limitations}

The study is based on a unique historical data source which allows us to follow an almost complete cohort across their life-span. Although restricted to births in one hospital in Uppsala, this data has been shown to be representative of Sweden in 1915-1929. ${ }^{39}$ Moreover, this cohort provided us with the possibility to better assess the association between macrosomia and mortality since, in contrast to studies based in contemporary settings, birthweight was not affected by obstetric interventions such as today's planned 
caesarean-sections in cases of suspected macrosomia ${ }^{40}$. Other strengths include systematically testing for gender interactions, and examining associations not only with absolute birthweight but also with relative birthweight and with gestational age. The use of a family-based design is another important strength that benefits from the large numbers of siblings that we have in our cohort.

A potential limitation of this study is that observable socioeconomic characteristics may provide partial information, insofar as some parents of our cohort members were young adults who might still be consolidating their occupational position. Moreover, on other relevant confounders (e.g, maternal health status) we lack data altogether. Although these limitations are mitigated by our application of a sibling design, we cannot exclude the existence of residual temporal confounding (i.e., confounding by factors that differ between siblings). In addition, insofar as we identify siblings based on sharing the same biological mother, some heterogeneity will be introduced by the presence of half-siblings.

Another drawback in our design is that some decisions were driven by sample size limitations. Thus, we could not use the usual definition of low birthweight fixed at $<2,500 \mathrm{~g}$. and we used instead a higher cut of point $(<3,000 \mathrm{~g})$. Likewise, small numbers meant that we had to create a heterogeneous category of 'unmarried mothers' that combined single, divorced and widowed mothers.

\section{Implications for future research}

Our findings open new questions and hypotheses. Further studies focusing on specific causes of death by age intervals are needed. Such studies will allow assessment of whether the lack of association observed in this study between birth characteristics and mortality at older ages could reflect the offsetting effect of disease-specific associations in opposite directions. Previous studies, including ones also using the UBCoS Multigen dataset, suggest this might be the case; lower birthweight and SGA have been associated with higher rates of cardiovascular disease $\mathrm{e}^{7,38}$, while macrosomia has been associated with a higher rate of breast, prostate, endometrial and colon cancer ${ }^{4,15,41-43}$.

Our study suggests that the effect of lower birthweight and SGA, lasts longer across the life course (up to age 44) than the effect of preterm birth, although the effect of preterm is stronger during the first year of life. Further investigation is needed to confirm this evidence, which contradicts the general expectation, that gestational age is a stronger predictor of short and long-term survival than birthweight ${ }^{37,44}$.

\section{Conclusion}

Light, small, and preterm newborns have a higher rate of mortality. These associations vary by age and measure under scrutiny. The associations with birthweight and gestational age were mostly confirmed in the sibling analysis, indicating that any residual maternal confounding is limited. Our findings support the message that policies oriented towards improving population health should invest in improving birth outcomes and hence, in maternal health. 


\section{Conflict of interest}

None

\section{$\underline{\text { Acknowledgements }}$}

This study was supported by "Methods in register-based research in Life course and social epidemiology" (funded by VR\#2013-5104, PI Koupil), "Social mobility and health among Swedish men and women born 1915-2010" (funded by FORTE \# 2013-1084, PI Koupil), Swedish Social Mobility Network (funded by FORTE \#2014-2693, PI Koupil),"New perspectives on the interplay between environmental factors, social issues and health" (SIMSAM-Lund Early-life funded by VR \# 2013-5474 PI Rignell-Hydbom) and Forte-centre: Human society as a life long determinant of human health " (funded by FORTE \#2006-1518, PI Lundberg).

\section{$\underline{\text { References }}$}

1. Breslau N, Johnson EO, Lucia VC. Academic achievement of low birthweight children at age 11: The role of cognitive abilities at school entry. J Abnorm Child Psych. Aug 2001;29(4):273-279.

2. Tong S, Baghurst P, McMichael A. Birthweight and cognitive development during childhood. Journal of paediatrics and child health. Mar 2006;42(3):98-103.

3. Godfrey KM, Barker DJ. Fetal programming and adult health. Public health nutrition. Apr 2001;4(2B):611-624.

4. Barker DJ. Fetal origins of coronary heart disease. Bmj. Jul 15 1995;311(6998):171-174.

5. Barker DJ, Hales CN, Fall CH, Osmond C, Phipps K, Clark PM. Type 2 (non-insulindependent) diabetes mellitus, hypertension and hyperlipidaemia (syndrome $\mathrm{X}$ ): relation to reduced fetal growth. Diabetologia. Jan 1993;36(1):62-67.

6. Gillman MW. A life course approach to obesity. In: Diana K, Ben-Shlomo Y, eds. A life course approach to chronic disease epidemiology. Oxford: Oxford University Press; 2004:189-217.

7. Leon DA, Lithell HO, Vagero D, et al. Reduced fetal growth rate and increased risk of death from ischaemic heart disease: cohort study of 15000 Swedish men and women born 1915-29. BMJ. Jul 25 1998;317(7153):241-245.

8. Risnes KR, Vatten LJ, Baker JL, et al. Birthweight and mortality in adulthood: a systematic review and meta-analysis. International journal of epidemiology. Jun 2011;40(3):647-661.

9. Baker JL, Olsen LW, Sorensen TIA. Weight at birth and all-cause mortality in adulthood. Epidemiology. Mar 2008;19(2):197-203.

10. Wilcox AJ, Russell IT. Birthweight and perinatal mortality: II. On weight-specific mortality. International journal of epidemiology. Sep 1983;12(3):319-325.

11. Power C, Li L. Cohort study of birthweight, mortality, and disability. Bmj. Mar 25 2000;320(7238):840-841.

12. Friedlander Y, Paltiel O, Deutsch L, et al. Birthweight and relationship with infant, child and adult mortality in the Jerusalem perinatal study. Paediatric and perinatal epidemiology. Oct 2003;17(4):398-406. 
13. Kajantie E, Osmond C, Barker DJP, Forsen T, Phillips DIW, Eriksson JG. Size at birth as a predictor of mortality in adulthood: a follow-up of 350000 person-years. International journal of epidemiology. Jun 2005;34(3):655-663.

14. Malin GL, Morris RK, Riley R, Teune MJ, Khan KS. When is birthweight at term abnormally low? A systematic review and meta-analysis of the association and predictive ability of current birthweight standards for neonatal outcomes. BJOG. 2014;121(5):515526.

15. Sovio U, Jones R, Dos Santos Silva I, Koupil I. Birth size and survival in breast cancer patients from the Uppsala Birth Cohort Study. Cancer causes \& control : CCC. Sep 2013;24(9):1643-1651.

16. Andersen AM, Osler M. Birth dimensions, parental mortality, and mortality in early adult age: a cohort study of Danish men born in 1953. International journal of epidemiology. Feb 2004;33(1):92-99.

17. Eriksson M, Wallander MA, Krakau I, Wedel H, Svardsudd K. The impact of birth weight on coronary heart disease morbidity and mortality in a birth cohort followed up for 85 years: a population-based study of men born in 1913. Journal of internal medicine. Dec 2004;256(6):472-481.

18. Smith GD, Hart C, Blane D, Gillis C, Hawthorne V. Lifetime socioeconomic position and mortality: prospective observational study. Bmj. Feb 22 1997;314(7080):547-552.

19. Gluckman P, Hanson M. Developmental Origins of Health and Disease. Cambridge Cambridge University Press; 2006.

20. Class QA, Rickert ME, Lichtenstein P, D'Onofrio BM. Birth weight, physical morbidity, and mortality: a population-based sibling-comparison study. American journal of epidemiology. Mar 1 2014;179(5):550-558.

21. Joseph KS, Kramer MS. Review of the evidence on fetal and early childhood antecedents of adult chronic disease. Epidemiologic reviews. 1996;18(2):158-174.

22. Barker D. Fetal and infant origins of adult disease. London: Wiley-Blackwell; 1992.

23. Kuh D, Ben-Shlomo Y, Lynch J, Hallqvist J, Power C. Life course epidemiology. Journal of epidemiology and community health. Oct 2003;57(10):778-783.

24. Maggi S, Irwin LJ, Siddiqi A, Hertzman C. The social determinants of early child development: an overview. Journal of paediatrics and child health. Nov 2010;46(11):627-635.

25. Juárez SP, Merlo J. Revisiting the effect of maternal smoking during pregnancy on offspring birthweight: a quasi-experimental sibling analysis in Sweden. PloS one. 2013;8(4):e61734.

26. Koupil I. The Uppsala studies on developmental origins of health and disease. Journal of internal medicine. May 2007;261(5):426-436.

27. Koupil I, Goodman A. Health Equity: A life course approach. Public Service Review: European Union. 2011;11(82):3.

28. Cunningham FG, Leveno KJ, Bloom SL, Hauth JC, Gistrap LC, Wenstrom KD. Williams Obstetrics. 22nd ed. New York: McGraw-Hill; 2005.

29. Kramer MS, Platt RW, Wen SW, et al. A new and improved population-based Canadian reference for birth weight for gestational age. Pediatrics. Aug 2001;108(2):E35.

30. Meddelanden i samordningsfrågor [Report on co-ordination issues]. Stockholm: Statistics Sweden;1989.

31. Goodman A, Gisselman MD, Koupil I. Birth characteristics and early-life social charactristics predict unequal educational outcomes across the life course and across generations. Longitudinal and Life Course Studies. 2010;1(4):317-338.

32. Mathers CD, Bernard C, Iburg MK, et al. Global Burden of Disease in 2002: data sources, methods and results. 2003 World Health Organization: Geneva. 
33. Clayton D, Hill M. Statistical Models in Epidemiology. Oxford: Oxford Science Publications; 1993.

34. Mann V, De Stavola BL, Leon DA. Separating within and between effects in family studies: an application to the study of blood pressure in children. Stat Med. Sep 17 2004;23(17):2745-2756.

35. Goodman A, Heshmati A, Malki N, Koupil I. Associations Between Birth Characteristics and Eating Disorders Across the Life Course: Findings From 2 Million Males and Females Born in Sweden, 1975-1998. American journal of epidemiology. Apr 1 2014;179(7):852-863.

36. Frisell T, Oberg S, Kuja-Halkola R, Sjolander A. Sibling Comparison Designs Bias From Non-Shared Confounders and Measurement Error. Epidemiology. Sep 2012;23(5):713720 .

37. Swamy GK, Ostbye T, Skjaerven R. Association of preterm birth with long-term survival, reproduction, and next-generation preterm birth. Jama-J Am Med Assoc. Mar 26 2008;299(12):1429-1436.

38. Koupil I, Leon DA, Lithell HO. Length of gestation is associated with mortality from cerebrovascular disease. Journal of epidemiology and community health. Jun 2005;59(6):473-474.

39. Rajaleid K, Manor O, Koupil I. Does the strength of the association between foetal growth rate and ischaemic heart disease mortality differ by social circumstances in early or later life? Journal of epidemiology and community health. May 2008;62(5).

40. Chauhan SP, Grobman WA, Gherman RA, et al. Suspicion and treatment of the macrosomic fetus: A review. Am J Obstet Gynecol. Aug 2005;193(2):332-346.

41. Barker DJP. In utero programming of chronic disease. Clin Sci. Aug 1998;95(2):115-128.

42. Silva dos Santos I, De Stavola B, McCormack V. Factors and subsequent risk of breast cancer. Birth size and breast cancer risk: re-analysis of individual participant data from 32 studies. PLoS Med. . 2008;5(9):1372-1386.

43. Ross JA. High birthweight and cancer: Evidence and implications. Cancer Epidem Biomar. Jan 2006;15(1):1-2.

44. Wilcox AJ. On the importance - and the unimportance - of birthweight. International journal of epidemiology. Dec 2001;30(6):1233-1241. 


\section{$\underline{\text { Appendix } 1 \text { - Supplementary Material }}$}

\section{Standardised birthweight for gestational age}

We first cleaned the data to identify infants with implausibly large birthweights given their gestational age. Following Ekholm et al. (2005) these were defined as gestational age $\leq 28$ completed weeks and birthweight $>2000$ g, gestational age 29-30 weeks and birthweight $>2500 \mathrm{~g}$, gestational age 31-32 weeks and birthweight $>3000 \mathrm{~g}$, and gestational age 33 or 34 weeks and birthweight $>3500 \mathrm{~g}$. We also added a further exclusion category of gestational age $\leq 25$ weeks and birthweight $>1500 \mathrm{~g}$. This identified a total of 83 children with incompatible birthweights and gestational ages, for whom we recoded both birthweight and gestational age as missing.

We then calculated standardised birthweight for gestational age on week-by-week basis separately for males and females. This was done using the observed mean and standard deviation for that week within the UBCoS cohort for the 13599 infants born at 30 or more completed weeks (i.e. an internal reference). For the 86 children born at 22-29 completed weeks, there were insufficient numbers of children in each category to use this internal reference method and we therefore used external reference data. Because no normative data for this range of gestational lengths exists for this historical population we instead used data from a large population-based sample of Canadian births from 1994-6 (Kramer et al., 2001). This was selected as the only reference data we could find which presents means and standard deviations for as low as 22 weeks; by contrast the youngest reference data we could find from Swedish reference data was 28 weeks (Niklasson et al., 1991). The Canadian data also has the advantaged of presenting the results separately by sex and in tables (and not just in graphs) and of having used sophisticated techniques to clean and smooth the data. The infants in this Canadian reference data weighed an average of $162 \mathrm{~g}$ less than the Uppsala sample, however, with no evidence of a difference in the size of this offset across the 22-29 week range or between boys and girls (p-values for interaction>0.7). We therefore again followed the methodology of Ekholm et al. (2005) in always adding $162 \mathrm{~g}$ to the mean of the Canadian reference data before calculating birthweight for gestational age in our cohort, but leaving the value of the standard deviations unchanged. For the six infants born at 21 completed weeks or less, we left their birthweight for gestational age as missing.

\section{References}

Ekholm, K., J. Carstensen, O. Finnstrom, and G. Sydsjo. 2005. The probability of giving birth among women who were born preterm or with impaired fetal growth: a Swedish population-based registry study. Am J Epidemiol 161:725-33.

Kramer, M.S., R.W. Platt, S.W. Wen, K.S. Joseph, A. Allen, M. Abrahamowicz, B. Blondel, and G. Breart. 2001. A new and improved population-based Canadian reference for birth weight for gestational age. Pediatrics 108:E35.

Niklasson, A., A. Ericson, J.G. Fryer, J. Karlberg, C. Lawrence, and P. Karlberg. 1991. An update of the Swedish reference standards for weight, length and head circumference at birth for given gestational age (1977-1981). Acta Paediatr Scand 80:756-62. 


\section{Comparison of between-mother and within-mother effects}

Among our explanatory variables, maternal age and the offspring birth characteristics are primarily properties of individual children not families. This allowed us to make withinfamily comparisons of the effect of these characteristics, and so examine whether any overall associations we saw might reflect residual confounding by family (mostly maternal) characteristics. To do this we created two versions of each child variable to be included into Cox proportional hazards models, a 'between-mother' version representing the average characteristic of all the offspring of each mother (e.g. their mean gestational age) and a 'within mother' version representing the departure of each child from that mean. The general form of the fitted Cox proportional hazards model for these analyses is:

$h_{j k}(t)=h_{0}(t) \exp \left(\beta_{1} \bar{y}_{j}+\beta_{2}\left(y_{j k}-\bar{y}_{k}\right)+\alpha_{1} Z_{1 j k}+\alpha_{2} Z_{2 j k}+\ldots\right)$

where $h_{j k}(t)$ ' represents the hazard of dying at age $t$ for child $j$ in family $k, h_{0}(t)$ is the baseline hazard at time $t ; \bar{y}_{k}$ is the average value of $y$ (the variable of interest, for example: birthweight categorized into 1 ' $L B W$ '- and 0 'not LBW') across the kth mother's offspring (range 0 to 1, equivalent to the proportion of mother's offspring born

with LBW); $\left(\mathrm{y}_{\mathrm{jk}}-\overline{\mathrm{y}}_{\mathrm{k}}\right)$ is the departure of the jth child of the kth mother from that average (range -1 to 1 , and is necessarily zero for children with no siblings); and $Z_{1 \mathrm{jk}}, Z_{2 \mathrm{jk}}$, etc. are other variables adjusted for in the model, while $\beta_{1}, \beta_{2}, \alpha_{1}$, etc are associated coefficients. In this model, $\beta_{1}$ captures the between-mother effect of $y$ and $\beta_{2}$ captures the withinmother effect.

To test for residual confounding due to maternal characteristics we compared the estimated effects of the between-mother and within-mother variables, that is we tested whether $\beta_{1}=\beta_{2}$. If the within-mother effect was significantly different from the betweenmother effect we interpreted this as evidence of residual maternal-level confounding (Mann et al 2004). If maternal-level confounding were generating spurious associations due to positive confounding for example, then one would expect the within-mother effect $\left(\beta_{2}\right)$ to be weaker than the between-mother effect; if maternal-level confounding were the entire explanation for any association, one would expect $\beta_{2}$ to be non-significantly different from zero.

\section{References}

Mann V, De Stavola BL, Leon DA. Separating within and between effects in family studies: an application to the study of blood pressure in children. Stat Med. 2004;23(17):2745-56. 
Birthweight cross-tabulated against gestational age

\begin{tabular}{|c|c|c|c|c|c|c|c|}
\hline $\begin{array}{l}\text { Gestational } \\
\text { Age }\end{array}$ & $\mathbf{N}$ & Mean & $\begin{array}{l}\text { Standard } \\
\text { deviation }\end{array}$ & Min & Max & P10 & p90 \\
\hline 22 & 7 & 709 & 182 & 510 & 1000 & 510 & 1000 \\
\hline 23 & 2 & 780 & 141 & 680 & 880 & 680 & 880 \\
\hline 24 & 4 & 845 & 245 & 560 & 1150 & 560 & 1150 \\
\hline 25 & 6 & 970 & 158 & 840 & 1240 & 840 & 1240 \\
\hline 26 & 9 & 1020 & 133 & 750 & 1200 & 750 & 1200 \\
\hline 27 & 7 & 1203 & 174 & 1010 & 1440 & 1010 & 1440 \\
\hline 28 & 12 & 1331 & 237 & 990 & 1700 & 1030 & 1680 \\
\hline 29 & 19 & 1537 & 425 & 900 & 2400 & 1060 & 2400 \\
\hline 30 & 15 & 1788 & 311 & 1200 & 2400 & 1510 & 2230 \\
\hline 31 & 35 & 1924 & 537 & 1050 & 2970 & 1290 & 2850 \\
\hline 32 & 41 & 2190 & 463 & 1360 & 2990 & 1570 & 2790 \\
\hline 33 & 85 & 2423 & 537 & 1120 & 3495 & 1730 & 3170 \\
\hline 34 & 135 & 2567 & 485 & 1300 & 3500 & 1950 & 3230 \\
\hline 35 & 210 & 2980 & 591 & 1080 & 4910 & 2260 & 3790 \\
\hline 36 & 410 & 3053 & 518 & 1250 & 5250 & 2430 & 3700 \\
\hline 37 & 742 & 3194 & 478 & 1400 & 4490 & 2610 & 3800 \\
\hline 38 & 1472 & 3307 & 466 & 1400 & 5370 & 2730 & 3880 \\
\hline 39 & 2675 & 3439 & 445 & 1960 & 5350 & 2890 & 4000 \\
\hline 40 & 3159 & 3546 & 456 & 1830 & 5350 & 3000 & 4140 \\
\hline 41 & 1999 & 3624 & 476 & 1990 & 5500 & 3050 & 4210 \\
\hline 42 & 905 & 3655 & 494 & 2260 & 5300 & 3020 & 4310 \\
\hline 43 & 342 & 3613 & 508 & 2310 & 4850 & 3000 & 4335 \\
\hline 44 & 155 & 3612 & 534 & 1870 & 5300 & 2900 & 4260 \\
\hline 45 & 78 & 3631 & 510 & 2090 & 5500 & 3050 & 4220 \\
\hline 46 & 36 & 3739 & 620 & 2600 & 5260 & 3010 & 4600 \\
\hline 47 & 4 & 3715 & 600 & 3150 & 4520 & 3150 & 4520 \\
\hline Total & 12564 & 3431 & 553 & 510 & 5500 & 2790 & 4100 \\
\hline
\end{tabular}

